\title{
Schwann cell lamellipodia regulate cell-cell interactions and phagocytosis
}

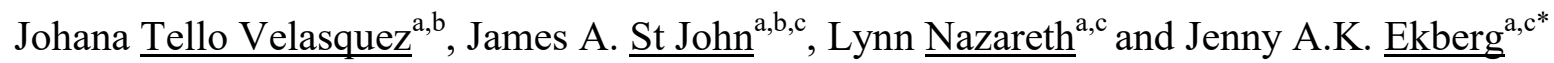

${ }^{a}$ Griffith Institute for Drug Discovery, 170 Kessels Rd, Griffith University, Nathan 4111, Queensland, Australia

${ }^{\mathrm{b}}$ Clem Jones Centre for Neurobiology and Stem Cell Research, 170 Kessels Rd, Griffith University, Brisbane, 4111, QLD, Australia

${ }^{c}$ Menzies Health Institute Queensland, Parklands Drive, Griffith University, Southport 4222, QLD, Australia.

Short running title: Schwann cell lamellipodia regulate cell contacts and phagocytosis Author contributions: The manuscript was written by all authors

Conflicts of interest: none.

*Corresponding author:

Jenny Ekberg

Email: j.ekberg@griffith.edu.au

Menzies Health Institute Queensland, Parklands Drive, Griffith University, Southport, 4222, QLD, Australia. 


\section{Abstract}

Lamellipodia in Schwann cells (SCs) are crucial for myelination, but their other biological functions remain largely uncharacterised. Two types of lamellipodia exist in SCs: axial lamellipodia at the outermost edge of the cell processes, and radial lamellipodia appearing peripherally along the entire cell. We have previously shown that radial lamellipodia on olfactory glia (olfactory ensheathing cells; OECs) promote cell-cell adhesion, contactmediated migration and phagocytosis. Here we have investigated whether lamellipodia in SCs have similar roles. Using live-cell imaging, we show that the radial lamellipodia in SCs are highly motile, appear at multiple cellular sites and rapidly move in a wave-like manner. We found that axial and radial lamellipodia had strikingly different roles and are regulated by different intracellular pathways. Axial lamellipodia initiated interactions with other SCs and with neurons by contacting radial lamellipodia on SCs, and budding neurites/axons. Most SCSC interactions resulted in repulsion, and, lamellipodial activity (unlike in OECs) did not promote contact-mediated migration. We show that lamellipodia are crucial for SC-mediated phagocytosis of both axonal debris and bacteria, and demonstrated that inhibition of lamellipodial activity by blocking the Rho/Rac pathways also inhibits phagocytosis. We also show that heregulin, which induces SC differentiation and maturation, alters lamellipodial behaviour but does not affect phagocytic activity. Overall, the results show that SC lamellipodia are important for cell interactions and phagocytosis. 


\section{Highlights}

- Schwann cells have motile lamellipodia that regulate cell-cell contact.

- Lamellipodia are important for phagocytic activity.

- Schwann cell lamellipodia are different to those in olfactory ensheathing cells in that radial lamellipodia do not drive contact-mediated migration.

Key words: glia, bacteria, heregulin, migration, lamellae

JE, JT and LN performed the laboratory work; all authors interpreted the data; JE wrote the draft of the manuscript; all authors edited the manuscript. All authors have approved the final article. 


\section{Introduction}

Schwann cells (SCs) are the glia of the peripheral nerves that myelinate and provide support for axons. During development, normal maintenance in the adult and during regeneration of nerves after injury or disease, SCs interact with other cells via lamellipodia that protrude from the leading edges of the cell (axial lamellipodia) and along the cells (radial lamellipodia). SCs originate from the neural crest, and migrate longitudinally along bundles of developing axons, to finally extend radial (peripheral) processes to initiate myelination [13]. Myelination also requires sorting of axons depending on size; only axons with a diameter over $1 \mu \mathrm{m}$ become myelinated. SCs in contact with such axons become mature myelinating SCs, enwrapping the axons in a jelly roll-like manner to create a thick myelin sheet [reviewed by 4]. Thus, the roles of the lamellipodia differ depending on the differentiation state of the SCs. While the roles of lamellipodia in SC migration [5-11] and myelination $[1,3,5,12,13]$ has been characterized, there are several key cellular functions in which the roles of lamellipodia remains unknown. These include (1) the dynamic behaviour of lamellipodia in real time, (2) the roles of lamellipodia in SC-SC contacts (including contact-mediated migration), (3) how lamellipodia mediate contacts between SCs and emerging axons, and (4) the roles of lamellipodia in SC-mediated phagocytosis of cell debris and bacteria.

SC lamellipodia are crucial for migration and myelination: SCs exhibit three migratory phenotypes (unipolar, bipolar and multipolar, out of which bipolar is the most common). The phenotypes are malleable and can transform into one another [11]. All phenotypes exhibit a leading edge lamellipodium (leading front) dependent on F-actin polymerization, and a polarized distribution of myosin II (which is higher at the leading edge) [11]. The generation of extensions, or cytoplasmic protusions, is regulated by signals from both the extracellular matrix and from the axons [2]. Small Rho GTPases (in particular Rac and Rho), activated 
mainly by $\beta 1$ integrins expressed on the cell surface of SCs, exert strong influence on SC migration, morphology (production of lamellipodia and ruffles) and cell-cell or cell-axon interactions. Interactions between laminins in the environment and $\beta 1$-integrins on the cell surface are crucial regulators of SC proliferation, maturation and differentiation $[1-3,6,14]$. These interactions regulate phenotypical and behavioral transitions of SCs from an elongated, migratory type to a phenotype extending active radial cytoplasmic protrusions crucial for myelination [2]. Whilst radial lamellae are particularly important for myelination, both axial and radial lamellipodia are crucial for migration. Laminin-induced $\beta 1$-integrin signalling leads to activation of lymphoid cell kinase (Lck), a tyrosine kinase which, via paxillin and the adapter molecule CrkII, upregulates the levels of active Rac1. This induces the formation of radial lamellipodia which promote both migration and myelination [5]. While the roles of lamellipodia in SC migration and myelination have been extensively studied, their specific role in cell-cell contact mediated migration has not been determined.

SC phenotype and behaviour are also regulated by neuregulins, a family of growth factors which regulate multiple key cellular functions such as proliferation, differentiation and survival [15]. Neuregulins are produced by sensory neurons, spinal cord motor neurons and autonomic neurons, and act as ligands for some members of the erbB family, including the EGF receptor, erbB2, erbB3 and erbBa [16]. The signaling cascades and biological responses activated by neuregulins are cell-type specific $[17,18]$. SCs express erbB2 and erbB3 [19], and for SCs, neuregulins promote differentiation [20], motility and migration [21] as well as proliferation [22]. These effects, however, vary depending on the SC subtype (myelinating versus non-myelinating) and developmental stage [reviewed by 23]. Neuregulin 1 (NRG; of which heregulin is an isoform, also known as NRG1 Type 1) is known to stimulate SC migration by inducing the formation of a protein complex containing $\alpha 5 \beta 1$ integrin (a fibronectin receptor), ErbB2 and focal adhesion kinase (FAK). The level of this complex is 
significantly increased in SCs after nerve injury, resulting in concentration of the complex component at the leading edge [10]. Whilst it is clear that radial lamellipodia are crucial for maintained SC-axon contacts and myelination, their roles in establishing contact with emerging axons/neurites, significant for development and axon regeneration, remain unknown.

One key SC function for which the role of lamellipodia has not been characterised is phagocytosis. SCs have key roles role during Wallerian degeneration for which lamellipodial activity may be important, in particular in phagocytosing myelin debris, reflected in the presence of vacuoles and degenerated myelin inside the cell body. After a nerve injury, SCs become de-differentiated or activated, and phagocytose the damaged myelin and dead neurons [24]. Studies have suggested that this phagocytic activity occurs due to structural changes within the cells, including the formation of phagocytic processes (short cytoplasmic extensions) $[25,26]$, however the roles of SCs lamellipodia in phagocytosis are to date uncharacterised.

We have previously demonstrated that in olfactory ensheathing cells (OECs), the glia of the olfactory nervous system, radial lamellipodia have important roles in cell-cell contacts, contact-mediated migration and phagocytosis [8,9, 27-31]. OECs exhibit rapidly changing phenotypes with the lamellipodia driving behaviour and cell interactions. Specifically, we have shown that radial lamellipodia mediate cell-cell contact-mediated migration [30]. Here, we determined the roles of SC lamellipodia in cell-cell contacts (including contact-mediated migration) and phagocytosis, and determined whether the Rac/Rho pathways and heregulin modulate key behaviours in SCs related to lamellipodial activity. 


\section{Materials and methods}

$S C$ culture: SCs were cultured from S100ß-DsRed transgenic mice [30], in which the S100ß promoter drives expression of DsRed, resulting in expression of the bright fluorescent DsRed protein in all glial cells. All procedures were carried out with the approval of the Griffith University Animal Ethics Committee under the guidelines of the Australian Commonwealth Office of the Gene Technology Regulator. S100ß-DsRed postnatal day 7 (P7) pups were decapitated followed by dissection of dorsal root ganglia (DRG) from the spinal cord. Whole DRG were added to 24-well plates previously coated with matrigel (BD Bioscience, 1:10) in small droplets of glial medium (Dulbecco's Modified Eagle Medium containing 10\% fetal bovine serum, G5 supplement (Gibco), gentamicin at $50 \mathrm{mg} / \mathrm{ml}$ (Gibco) and L-glutamine at $200 \mu \mathrm{M})$. Cultures were maintained in glial medium at $37^{\circ} \mathrm{C}$ with $5 \% \mathrm{CO}_{2}$ for 5 days. After SCs had emerged from the DRGs and reached confluence, they were replated, on 24- or 8well matrigel-coated glass plates for imaging.

DRG neuron culture: DRG neuron cultures were established as described previously (Daly et al., 2004) with a slightly modified enzymatic treatment protocol. DRG were dissected from postnatal day 7 (P7) S100ß-DsRed mice and treated with $0.25 \%$ trypsin and $0.1 \%$ collagenase for $45 \mathrm{~min}$ at $37^{\circ} \mathrm{C}$, followed by mechanical dissociation and centrifugation. Then neurons were passed through a $50 \mu \mathrm{m}$ pore size cell strainer and plated onto glass plates as described for the SCs, in a 1:1 neuron-to-SC ratio. Cells were imaged after $24 \mathrm{~h}$ when neurites started to emerge from the DRG neurons.

In vivo and in vitro identification of SCs: Fluorescent whole mount preparations of the S100ß-DsRed spinal column were imaged using an Olympus SZX7 microscope to examine the expression of the DsRed protein through the spinal column and peripheral nerves. 
Cultured cells were fixed with $4 \%$ paraformaldehyde (PFA) and posteriorly blocked with $2 \%$ BSA with PBS with $0.3 \%$ Triton-X for $1 \mathrm{~h}$, followed by overnight incubation with the primary antibodies: rabbit polyclonal antibodies against S100ß (1:500, Dako, Z031129-2,) and mouse anti-human p75 neurotrophin receptor antibodies (Biosensis, 1:400). After 3 washes with PBS plus Triton-X, cells were incubated for $1 \mathrm{~h}$ room temperature with secondary antibodies donkey anti-rabbit Alexa 488 (1:400, Life Technologies, A-21202) and goat anti-mouse Alexa Fluor 488 (1:200; Invitrogen) respectively. Nuclei were stained with 4', 6-diamidino-2-phenylindole (DAPI). Cells were imaged using confocal fluorescence and bright-field microscopy to determine the purity of the cultured SCs. The percentage of cells that expressed DsRed and were positive for anti-S100 $\beta$ antibody labelling was calculated by manual counting of three random fields per well per culture. For some imaging studies, cells were stained with calcein-AM (green fluorescence; Thermo Fisher Scientific).

Live cell imaging: SCs were plated onto glass plates and imaged in $\mathrm{CO}_{2}$-independent medium (Invitrogen). Time-lapse images were taken every $15 \mathrm{sec}$ over periods of 40-60 min using a Hamamatsu digital camera on an Olympus IX81 CellR equipped with a $37^{\circ} \mathrm{C}$ incubator chamber. Images were compiled using Axiovision Rel 4.6.3 (Zeiss, Germany). For some assays, confocal live cell imaging images were taken every 3 min using an Olympus CV1000 confocal microscope.

Quantification of lamellipodia and migration rates: Time-lapse image sequences were analysed with Axiovision 4.6.3 (Zeiss, Germany). The number of lamellipodia that appeared on cell processes was summed over the recording period. Radial lamellipodia that were clearly distinguished from the leading edge of both processes were determined and the number recorded. Image $\mathrm{J}$ software (freehand/segmented line tools) was used to measure the area of radial lamellipodia. The cell migration rate over the course of the live-cell imaging 
period was calculated using the distance measurement tool of Axiovision software. To determine the effect of heuregulin on SC lamellipodia, cells were treated with heregulin (SRP3055 SIGMA) at different concentrations (10 ng/ml, $20 \mathrm{ng} / \mathrm{ml}, 50 \mathrm{ng} / \mathrm{ml}$ and $100 \mathrm{ng} / \mathrm{ml})$. Time-lapse images were taken every $5 \mathrm{~min}$ for $30 \mathrm{~min}$ after treatment. Number of lamellipodia and area of lamellipodia were quantified and analysed using Image J.

Phagocytosis assays: To determine the level of phagocytic activity in SCs, cells in control medium or in medium supplemented with heregulin $\beta 1(50 \mathrm{ng} / \mathrm{ml})$, were incubated for $3 \mathrm{~h}$ and $12 \mathrm{~h}$ with green fluorescent axonal debris generated from OMP-ZsGreen mice as previously described [9]. The same density $\left(6 \times 10^{3}\right.$ cells/chamber in 8 -well glass chamber slides) and the same amount of axonal debris were added to both treatments. After $3 \mathrm{~h}$ or 12 $\mathrm{h}$, the medium was removed and the wells washed three times with Hank's balanced salt solution (HBSS) to remove extracellular debris. Cells were fixed for $10 \mathrm{~min}$ in $4 \%$ PFA and imaged using confocal microscopy. For quantification of phagocytosis of axonal debris, confocal microscope images were taken keeping the laser and imaging parameters constant and ensuring the green fluorescent channel was not saturated. Amount of internalised axonal debris was quantified by measuring the mean intensity of green fluorescence (0-255 range) within the entire cell boundaries as defined by the DsRed fluorescence of the cells using ImageJ. A total of at least ten cells per view field for three replicates were completed for each treatment.

Additionally, phagocytosis assays were carried out using live and heat-killed FITC labelled Escherichia coli bacteria. Briefly, E. coli were grown in liquid Luria broth (LB) media with shaking or on LB agar plates. E. coli was labelled with fluorescein 5-isothiocyanate (FITC, Sigma-Aldrich) using a modification of a previously described method [32]. Live and heatkilled bacteria were washed 5 times by centrifugation and resuspended in $5 \mathrm{ml}$ of $0.1 \mathrm{M}$ 
sodium carbonate buffer, $\mathrm{pH} 8.6$ with final resuspension in $1 \mathrm{ml}$ of buffer. FITC $(1 \mathrm{mg} / \mathrm{ml}$ DMSO) was added at a ratio of $5 \mu \mathrm{l}$ to $1 \mathrm{ml}$ of the bacteria in sodium carbonate buffer for 18 $\mathrm{h}$ at $4^{\circ} \mathrm{C}$; then washed by centrifugation/resuspension in $0.1 \mathrm{M}$ sodium carbonate buffer, $\mathrm{pH}$ 8.6. Bacterial concentration was determined from optical density at $600 \mathrm{~nm}$. Solutions of bacteria were stored as frozen aliquots and freshly thawed for each experiment. Live cell imagining as described previously [28] was carried out to determine the roles of lamellipodia in the phagocytic process.

Assessing the effects of inhibiting key intracellular pathways on cell behaviour: To determine the roles of the Rac and Rho pathways in the generation of SC lamellipodia, inhibitors for these pathways were used. A Rac inhibitor (NSC23766, Sigma Aldrich) and a Rho inhibitor (Fasudil, Sigma Aldrich) were used at concentrations of 10, 20 and $50 \mu \mathrm{M}$ based on previous studies [12], and were added to the culture medium of SCs previously seeded in 8-well glass chambers at a density of 6000 cells/well. After 3, 12 and $24 \mathrm{~h}$ of treatment, cells were fixed with 4\% PFA and confocal microscope images were taken. Additionally, phagocytosis assays were carried out to determine the effect of these inhibitors in the phagocytic activity of SCs. Briefly, inhibitors at 10,20 and $50 \mu \mathrm{M}$ were added to SCs in combination with axonal debris (as previously describe in the phagocytosis assays section). Phagocytosis of axonal debris was analysed by confocal microscopy. Confocal microscope images were taken maintaining imaging settings allowing comparison between the treatments and the control. The mean intensity of green fluorescence (0-255 range) inside the cell was measured using ImageJ software. At least 10 cells $\mathrm{x}$ three replicates were analysed for each treatment.

\section{Statistical analysis:}

To determine whether the data was normally distributed, normality tests (skewness and excess kurtosis coefficients) were determined using SPSS Statistics 22 software. 
Measurements of morphological parameters were tested for statistical significance using oneway ANOVA with Tukey's and LSD post-hoc analyses. For phagocytosis assays, statistical significance was tested using one-way ANOVA with Tukey's post-hoc analysis. When the pvalue was less than 0.05 , the difference was regarded as statistically significant.

To determine SC migration rates (Fig. 5), 2000-6000 cells were seeded in the glass-bottomed chambers, and images were taken of five representative random fields in each well, constituting 40-44 cells per condition. Each experiment was repeated three times. For phagocytosis assays (Fig. 7G, Fig. 8E, F) and quantification of lamellipodia (Fig. 7E, F), cells were seeded at 6000 cells/well in glass-bottomed 8-well chambers. A total of at least ten cells per view field for three replicates were completed for each treatment. This comprised a total of 50-75 cells per group. The n-values for these experiments were based on our previous similar experiments $[8,9,30,31]$.

\section{Results}

\section{SCs exhibit highly motile lamellipodial protrusions}

To easily visualize lamellipodia in SCs, we used SCs from S100ß-DsRed transgenic mice [30]. In these mice, SCs in peripheral nerves are easily visible in whole-mount preparations and in cryostat sections due to the expression of the fluorescent DsRed protein in glial cells (Fig. 1A, B). SCs that expressed the DsRed protein in vivo were also immunoreactive for anti-S100 $\beta$ antibodies (Fig. 1B, C). Cultured SCs continued to express DsRed and were positive for anti-p75 neurotrophin (p75NTR) labelling (Fig. 1D-F), further confirming the identity of the cells as SCs [33]. Cultures of at least 95\% purity were obtained and used for further assays. 
We used time-lapse imaging of dispersed cultures of SCs to determine the behaviour of the cells in real time, with focus on cell-cell interactions and lamellipodia. SCs exhibited highly dynamic activity and rapidly altered their morphology to interact with neighbouring cells (Fig. 2A, Supplemental movie 1). Lamellipodia appeared at the leading edges (axial lamellipodia) and peripherally (along the shafts; radial lamellipodia) of the cells (arrows, Fig. 2A), and were clearly present at the site of initial contact between cells (arrow in Fig. 2A, time 3:00). Radial lamellipodia moved rapidly along the processes and cell body, similarly to the behaviour of radial lamellipodia in OECs that we have previously described [30]. When SCs were cultured at low density without contact with other cells, lamellipodia were less dynamic, and the cells typically had a bipolar morphology without large radial lamellipodia (Fig. 2B). We then examined the behavior of radial lamellipodia in cell-cell contacts at high magnification. When two neighboring SCs were in close proximity, lamellipodia (arrow, Fig. 2C) often with thin filopodia (arrowhead, Fig. 2C) emerged from both cells to initiate contact. When SCs were cultured at higher densities (so that cells were on top of each other, creating a three-dimensional structure), the morphology of the interacting lamellipodia exhibited extensive folding (Fig. 2D). When co-cultured under the same conditions with DRG neurons, the radial lamellipodia of the SCs interacted extensively with the axons (Fig. 2E). These results suggest that lamellipodia are important for contact between SCs and axons.

\section{SC lamellipodia mediate cell-cell interactions}

We examined the roles of lamellipodia in mediating SC-SC interactions by observing the cells over time using live cell imaging. Differential inference contract imaging (DIC) of isolated SCs which were close to neighbouring cells revealed that radial lamellipodia rapidly emerged and retracted within a few minutes, with lamellipodia on the same cell appearing to 
act independently of each other (Fig. 3A, B). In interactions between neighbouring cells, the majority of lamellipodial interactions (75\%) led to non-stable contact with rapid retraction of the lamellipodia within 10 min, which we denominated "repulsion" (Fig. 3D, E). However, one quarter of interactions led to stable contacts lasting more than $60 \mathrm{~min}$; we have classified these interactions as "adhesion" (Fig. 3C, E). The majority of interactions (70\%) between cells involved a leading edge (axial lamellipodium) contacting a radial (peripheral) lamellipodium on another cell. Just $\sim$ one-fifth of interactions between cells involved radial lamellipodia contacting other radial lamellipodia; while leading edge-to-leading edge interactions were infrequent ( $6 \%$; Fig. 3F).

In co-cultures of SCs and DRG neurons, axial lamellipodia (leading edges) of SCs initiated approximately $80 \%$ of contacts with the emerging DRG neurites, while only $\sim 20 \%$ of the SCaxon interactions were initiated by a radial lamellipodium (Fig. 4A, C). However, during prolonged contact between SCs and DRGs, emerging neurites from DRG axons interacted extensively with radial lamellipodia in SCs. The radial lamellipodia emerged often at some distance away from the neurite and then moved along the shaft of the SC to interact with the emerging neurites (Fig. 4B).

We have previously reported that peripheral lamellipodia in OECs are important for contactmediated migration [30]. OECs migrate faster at a high cell density than when plated at lower densities, and this is directly related to the number of radial lamellipodia in the cells [29, 31]. We therefore examined whether number of radial lamellipodia influenced the migration rate of SCs. As the number of lamellipodia in SCs increased with increased cell density (Fig. 2A, B), we examined the relationship between different cell densities and migration rate of individual SCs using single cell tracking. We found that in contrast to what we previously reported on OECs, SCs did not migrate faster at higher densities (Fig. 5A). We also examined whether the migration rate was related to the number of radial lamellipodia per cell, but 
again, no statistical correlation between the two parameters was found (Fig. 5B). Thus, despite the fact that radial lamellipodia in SCs have previously been shown to be important for migration [5], the number of radial lamellipodia in SCs in the current study did not influence cell-cell contact-mediated migration.

\section{SC lamellipodia mediate phagocytosis}

SCs are phagocytic cells, clearing debris after peripheral nerve damage [reviewed by 34,35 ] and are also capable of phagocytosing microorganisms [36]. As SCs interact with their external environment via lamellipodia, we investigated whether lamellipodia were involved in phagocytosis of cell debris and bacteria. We used live cell confocal imaging to visualize SCs cultured in the presence of fluorescently labelled cell debris (Fig. 6A), heat-killed E. coli bacteria (Fig. 6B), and live E. coli bacteria (Fig. 6C). The cell debris and bacteria were mainly detected by the axial lamellipodia, and then internalized with the cell debris or bacteria transported to the perinuclear region; radial lamellipodia appeared to participate in the internalization and transportation of debris into the cell (supplemental movies 2-4). In the particular case of live bacteria, the radial lamellipodia actively responded to and internalized bacteria; the lamellipodia in direct contact were markedly larger than cells not involved in phagocytosis. We confirmed that the cell debris and bacteria had been internalized using confocal imaging (Fig. 6D-F). Since we found that lamellipodia played an active role in the detection and/or internalisation of debris and bacteria, we examined below whether lamellipodia modulators such as heregulin and the Rac/Rho pathways may affected the phagocytic activity of SCs. 


\section{Heregulin modulates SC lamellipodia, but does not alter phagocytic activity}

Heregulin (also known as neuregulin-1) is known to act as an effective mitogen for human SCs [37], and its role in the regulation of cell morphology, particularly in the formation of membrane ruffles in different cell types, has been also widely described [reviewed by 38,39 ]. We therefore investigated if heregulin alters the formation and morphology of SC lamellipodia. We found that heregulin $(50 \mathrm{ng} / \mathrm{ml})$ dramatically altered lamellipodial morphology. In the presence of heregulin, the radial lamellipodia were broader and extended further away from the cell than in control cells. Further, heregulin reduced the number of small lamellipodia which are commonly present on SCs in control medium (Fig. 7A, B). We quantified the number of radial lamellipodia in SCs when cultured with different concentrations of heregulin $(10-50 \mathrm{ng} / \mathrm{ml})$ and found that there were significantly fewer radial lamellipodia in heregulin-treated cells in comparison to cells in control medium (between 15 to 30 min after heregulin addition; Fig. $7 \mathrm{C}$ ). We then measured the area of the lamellipodia and found that heregulin at $50 \mathrm{ng} / \mathrm{ml}$ significantly increased the area of the lamellipodia by over 2.5-fold (Fig. 7D). Thus, heregulin resulted in fewer, but larger lamellipodia.

As we have previously shown for OECs, changes in lamellipodial behaviour play an important role in modulating the phagocytic activity of the cell, with larger lamellipodia correlating with higher phagocytic activity [9]. Since heregulin exerted major effects on lamellipodia, we investigated whether heregulin altered the phagocytic activity of SCs. We cultured SCs with heregulin $(50 \mathrm{ng} / \mathrm{ml})$ and quantified the amount of cell debris that had been internalized after $3 \mathrm{~h}$ and $12 \mathrm{~h}$ by confocal imaging analysis (Fig. 7E). We found that heregulin did not alter the phagocytic activity of SCs at any of the time-points analyzed (Fig.

7F). The amount of phagocytosed debris increased over time $(12 \mathrm{~h})$ in both of the treatments in comparison with the $3 \mathrm{~h}$ time point (Fig. 7F); however no difference between control and heregulin-treated cells was observed at $12 \mathrm{~h}$. 


\section{The Rho and Rac signalling pathways regulate SC lamellipodia and phagocytic activity}

The Rho and Rac pathways are known to modulate the behaviour of lamellipodia in SCs. The Rac kinase pathway promotes the generation of radial lamellipodia, whilst Rho promotes the formation of stress fibers and regulates focal adhesions $[3,6,12]$. We examined whether inhibitors of the Rac and Rho pathways affected the phagocytic activity of SCs. We treated SCs with the Rac kinase pathway inhibitor NSC23766 and the Rho kinase inhibitor Fasudil at different concentrations $(10,20$ and $50 \mu \mathrm{M})$ for $3 \mathrm{~h}, 12 \mathrm{~h}$ and $24 \mathrm{~h}$. As expected, treatment with the Rac inhibitor reduced the size of radial lamellipodia (Fig. 8A, arrowheads), accompanied by an increase in size of axial lamellipodia (leading edges) (Fig. 8A, arrows). In contrast, cells treated with the Rho inhibitor were more elongated and exhibited long, thin extensions (Fig. 8B, arrows) with collapsed stress fibers; here, broad axial lamellipodia were sparse (Fig. 8B). A particularly striking feature was observed as a result of Rho inhibition: agglomerations of debris were attached to the cell surface (Fig. 8D), indicating that normal lamellipodia may be essential for the internalisation of debris. This correlates with the observation that cell debris is detected by the axial lamellipodia, and progressively internalised with the participation of the radial lamellipodia (Fig. 6, supplemental movies 24). At high concentration, the Rac inhibitor appeared to also mediate similar effects as the Rho inhibitor, suggesting that the inhibitor may also exert inhibition of the Rho pathway at high concentrations (Fig. 8C).

We then examined the effect of the Rac and Rho inhibitors on the phagocytic activity of the cells at different time-points after addition of cell debris ( $3 \mathrm{~h}, 12 \mathrm{~h}$ and $24 \mathrm{~h})$. At $3 \mathrm{~h}$ after addition of axonal debris, treatment with the Rac inhibitor caused a significant increase in the phagocytic activity at $3 \mathrm{~h}(42,63$ and 94\% increase in comparison to control at 10, 20 and 50 $\mu \mathrm{M}$, respectively; Fig. 8E), however, no statistically significant difference was detected between the different concentrations. The Rho inhibitor, at $10 \mu \mathrm{M}$, caused a large increase in 
the phagocytic activity in $121 \%$ over control; 20 and $50 \mu \mathrm{M}$ also showed a significant increase when compared with control (35 and 18\% respectively; Fig. $8 \mathrm{~F}$ ). In stark contrast, at later time points, phagocytic activity was reduced by both Rac and Rho inhibitors. At $12 \mathrm{~h}$, phagocytic activity reduced significantly in all the Rac inhibitor concentrations and in a concentration-dependent manner. Inhibition of Rho also caused significant reduction of the phagocytic activity; however no statistically significant concentration-dependence was detected at this time-point (Fig. 8F). At $24 \mathrm{~h}$ after addition of axonal debris, the inhibitors also reduced the phagocytic activity in the cells in a concentration-dependent manner (Fig. $8 \mathrm{E}, \mathrm{F})$

\section{Discussion}

Lamellipodia (membrane protrusions) in SCs have been reported to be crucial for SC migration [5-11] and for axonal sorting and myelination after activation of multiple signaling cascades by axons and the extracellular matrix $[1,3,5,12,13]$. However, other biological roles of SC lamellipodia have to date not been fully characterized. In particular, the dynamic behaviour of lamellipodia that mediate interactions with other cells, has not been determined in real time, and the roles of lamellipodia in SC phagocytosis are unknown. Here, we describe how motile peripheral lamellipodia in SCs mediate cell-cell communication between individual SCs. We showed that most SC-SC interactions occur between an axial lamellipodium (leading edge) in one cell, and a radial lamellipodium (peripheral lamellipodial wave) in the other cell. These interactions resulted primarily in repulsion, in contrast to what we have previously reported for olfactory ensheathing cells (OECs) In OECs, lamellipodial interactions result mainly in cell-cell adhesion, which is crucial for contact-mediated migration [30] as well as for proliferation [31]. We also show that in 
contrast to what we have shown for OECs, the activity of SC lamellipodia was not correlated with contact-mediated cell migration. OECs have been suggested to be superior to SCs for transplantation therapies due to their ability to migrate long distances into scar tissue [reviewed by $28,40,41,42]$. Thus, it is possible that the difference in the roles of lamellipodial behavior holds the key to why OECs migrate faster and further than SCs. It has, however, previously been shown that normal Rac activity is essential for SC motility $[5,21]$, suggesting that radial lamellipodia are important for SC migration, but not specifically for cell-cell contact-mediated migration.

We also show that SC lamellipodia were crucial for mediating SC-axon interactions in cocultures of SCs and DRG neurons. Here, we focused on the interactions between SCs and emerging neurites, rather than mature axons and myelination, since the roles of SC lamellipodia in myelination have been established $[1,3,5,12,13]$. Interactions between SCs and emerging neurites reflect the events important during development of the peripheral nervous system [1-3], as well as between SCs and axons that are regenerating after injury (reviewed by [43]), and the DRG neuron in vitro culture model of emerging axons reflect these events $[23,44]$. We found that axial lamellipodia initiated the majority of SC-axon interactions, whilst radial lamellipodia appeared to be critical for maintaining SC-axon contact over time. Radial lamellipodia are known to be key players in myelination; they selectively interact with neurons large enough to become myelinated in a 1:1 SC-to-axon relationship, and then expand in size to spiral-wrap the axon, thus becoming the thick insulating myelin layer. Therefore, the prolonged interaction between radial SC lamellipodia and axons may be a crucial mechanism for maintaining continuous SC-axon contact, as well as constitute the initiation of sorting and myelination later specifically mediated by radial lamellipodia. Although a link between cytoskeletal dynamics and myelination is widely 
accepted [1], the specific effector that modulates cytoskeletal organization in developing and myelinating SCs is not defined. It is likely that signaling involving integrins and extracellular matrix proteins mediate the contact between the radial lamellipodia and axons, enabling SCs to maintain the 1:1 relationship with axons resulting in myelination [2]. We treated SCs with the growth factor heregulin, which promotes SC differentiation and maturation $[18,37,45]$, and found that heregulin altered the behaviour of lamellipodia to become fewer, larger and broader, possibly reflecting the lamellipodial behaviour in SCs that promotes prolonged cellaxon contacts and myelination.

SCs can phagocytose axonal debris [reviewed by 34, 35] and bacteria [36], but it was previously not known whether lamellipodia were involved in SC phagocytosis. We imaged SCs over time in the presence of fluorescently labelled debris and E. coli bacteria, and showed that lamellipodia played an active role in detection and internalization of both bacteria and debris. Whilst heregulin treatment led to an increase in the size of SC lamellipodia, it had no effect on the phagocytic activity of the cells. After peripheral damage, SCs respond by de-differentiation, favouring a proliferative phenotype which is also able to remove myelin and axonal debris by phagocytosis. Conversely, mature differentiated SCs are not actively phagocytic in the non-perturbed PNS [46]. Thus, the heregulin-induced changes in lamellipodial behaviour may only be related to biological functions associated with mature SCs and not directly related to phagocytosis. We have previously reported that the alkaloid curcumin enhances the area and number of lamellipodia in both OECs and SCs, resulting in 10-fold increased phagocytic activity of OECs but having no effect on the phagocytic activity of SCs $[9,28]$. Thus, whilst lamellipodia are involved in SC phagocytosis, it is possible that the number and size of lamellipodia are not necessarily related to the phagocytic activity of the cells. 
The molecular mechanisms behind the cytoskeletal changes that lead to the formation of lamellipodia in SCs are not completely understood. The role of the cytoskeleton has been previously described as crucial for the sorting and myelination, as deletion of key cytoskeletal regulators (Fak, ILK, Rac1, Rho, and N-Wasp) in SCs leads to serious defects in these processes $[2,3,13,47]$. Small Rho GTPases, such as Rho and Rac, are key regulators of actin dynamics in different types of cells [48]; Rac is involved in membrane ruffling and formation of lamellipodia, whereas Rho mediates stress fiber formation [49]. In SCs, Rac and Rho affect cell motility and morphology changes [50]. Both Rho and Rac are crucial for normal myelination, with Rac being specifically important for the generation of radial lamellipodia in SCs $[3,5,6,12]$, acting downstream of $\beta 1$ integrins $[2,3,5]$.

Here, we verified that inhibition of Rac strongly reduced the formation of radial lamellipodia, accompanied by an increase in size of axial lamellipodia ("leading edges"). Inhibition of Rho caused an even more dramatic effect on SCs morphology with an overall prominent reduction in lamellipodia; axial lamellipodia in particular were largely absent; this is most likely due to the fact that Rho activity is crucial for the formation of microfilaments and focal adhesion points [48]. We found that sustained inhibition of both Rho and Rac significantly reduced the phagocytic activity in SCs, demonstrating that, even though lamellipodial size and number may not be important, lamellipodia are directly involved in SC-mediated phagocytosis. After inhibition of the Rac and Rho pathways, fluorescently labelled debris was attached to the cells rather than internalized into the cell. This effect was particularly prominent after Rho inhibition, indicating that the internalization of axon debris is regulated by the generation of filopodia and focal adhesion points. In the short term $(3 \mathrm{~h})$, however, Rac and Rho inhibition instead enhanced the internalization of cell debris. We do not know the mechanisms behind this phenomenon; it is possible that inhibition of Rho and Rac, in addition to inhibiting 
phagocytosis, also attenuates degradation of phagocytosed material due to inhibition of Factin. This may result in an increased accumulation of internalized material within the cells, which is particularly evident at the $3 \mathrm{~h}$ time-point. The roles of Rac and Rho GTPases in socalled professional phagocytes, in particular macrophages, are starting to emerge. For example, one previous study shows that Rac1 enhanced, whilst RhoA inhibited, the engulfment of apoptotic cells by macrophages in short-term $(1 \mathrm{~h})$ phagocytosis assays [51]. Another study revealed that Rac1 is tightly spatiotemporally regulated in phagocytic cells; at lamellipodial sites of phagocytosis, active Rac1 was required to form phagocytic cups consisting of actin patches; after closure of the phagocytic cup, Rac1 was down-regulated [52]. Whilst these data from macrophages may not correlate with our data from Schwann cells, it is clear small GTPases have important and complex roles in lamellipodia-mediated phagocytosis in a range of cell types, both professional and non-professional phagocytes (reviewed in [53])

In summary, our results suggest that Rac and Rho have distinct roles in the morphology and phagocytic activity of SCs. Inhibition of each of the pathways resulted in significant reduction of phagocytosis, suggesting that there a balance of Rho and Rac activity is necessary for normal phagocytic activity. This balance between these two pathways has been described previously as a crucial for normal cytoplasmic process extension and migration [54].

\section{Conclusion}

We have demonstrated that SCs exhibit highly motile and dynamic radial lamellipodia, as well as active axial lamellipodia (leading edges). The axial lamellipodia are responsible for searching the environment, detecting other cells and material to be phagocytosed, with radial 
lamellipodia maintaining longer term SC-axon contacts. We demonstrated that lamellipodia, both axial and radial, are essential for the phagocytic activity of the cells.

\section{Funding}

This work was supported by a Perry Cross Spinal Research Foundation grant to JSJ and JE, an Australian Research Council Discovery (ARC) Grant (DP0986294) to JE, an ARC Discovery grant (DP150104495) to JE and JSJ, and a Motor Accident Insurance Commission grant to JSJ and JE. The granting bodies had no role in the experimental design, interpretation, and writing of the report or decision to submit the article.

\section{Figure legends}

Figure 1. Schwann cell (SC) identification in vivo and in vitro. (A) Spinal nerve SCs in vivo. Ventral view of the dissected spinal column and peripheral nerves of a postnatal day 7 mouse pup. The S100ß-DsRed expression is visible within the peripheral nerves (populated by SCs) and spinal cord (populated by DsRed-expressing oligodendrocytes and chondrocytes). (B-C) SCs in a dorsal root ganglion (DRG) and spinal nerve in vivo. In cryostat sections of a DRG and attached peripheral nerve, SCs, which express S100ß-DsRed (B), were also immunolabelled with an S100 $\beta$ antibody (C). (D-F). Isolated, cultured and purified SCs in vitro. Cultured SCs expressed DsRed fluorescence (D) and were immunolabelled for the p75 neurotrophin receptor (p75ntr; E, green); merged images shown in (F). Scale bar $=400 \mu \mathrm{m}$ in A, $400200 \mu \mathrm{m}$ in B-C and $100 \mu \mathrm{m}$ in D-F. 
Figure 2. SC lamellipodia drive cell-cell and cell-axon interactions. (A) Typical lamellipodia in cultured SCs. Time-lapse confocal imaging of cultured SCs revealed numerous motile peripheral lamellipodia (arrows), which were prominent during interactions between cells. Time is shown in hours and min. (B) SCs without contact with other cells exhibited few lamellipodia. Merged differential inference contrast (DIC) and confocal fluorescence images show an isolated SC with few peripheral lamellipodia. (C-E) SCs interact with each other, and with axons, via lamellipodia and filopodia. (C) High magnification confocal imaging of interacting SCs revealed filopodia (arrowhead) and lamellipodia (arrow) projecting toward each other. (D) In higher density cultures, the interacting lamellipodia from two different cells exhibited more complex morphologies. (E) In co-cultures of SCs and DRG neurons in which all cells were stained with green calcein-AM, peripheral lamellipodia from SCs (yellow, i.e. red and green) interacted with axons (green). Scale bar $=50 \mu \mathrm{m}$ in A; $30 \mu \mathrm{m}$ in $\mathrm{B} ; 5 \mu \mathrm{m}$ in $\mathrm{C} ; 10 \mu \mathrm{m}$ in $\mathrm{D}, \mathrm{E}$.

Figure 3. Lamellipodia regulate SC-SC interactions, most of which result in repulsion. (A, B) Dynamic activity of lamellipodia in SCs. DIC and fluorescence (DsRed) images of a SC illustrate the dynamic, rapidly changing activity of peripheral lamellipodia; within 4 min (B) the lamellipodia emerge or retract. A neighbouring cell is partially visible at the bottom (asterisk). (C, D) Examples of lamellipodia-mediated SC-SC interactions resulting in adhesion (C) and repulsion (D). Adhesion was defined as a prolonged contact lasting for more than 60 min. (E) The majority of lamellipodia-mediated interactions between SCs resulted in repulsion. The bar graph represents the percentages of cell-cell interactions leading to adhesion (25\%) and repulsion (75\%) $(\mathrm{n}=24$ interactions). (F) Most interactions between SCs (70\%) involved the leading edge (axial lamellipodium; AL) of one cell, and a 
peripheral lamellipodial wave (radial lamellipodium, RL) of another cell $(n=80$ interactions). Scale bar $=30 \mu \mathrm{m}$ in $\mathrm{A} ; 15 \mu \mathrm{m}$ in $\mathrm{B}$ and $\mathrm{C}$.

Figure 4. The leading edge of SCs mediates initial contact with emerging DRG neurites, but radial lamellipodia maintain continued SC-neurite contact. (A) Example of a typical interaction between a SC and a DRG neurite. DIC time-lapse images show a SC with an active leading edge (axial lamellipodium; arrow) in close proximity to a DRG neuron $(\mathrm{N})$ in the process of extending neurites. At 4 min, filopodia (arrow with tail) extending from SC lamellipodium initiated contact with the nascent neurites. At 60 min, a radial lamellipodium (dotted line) emerged and moved to the contact site, and established contact with the neurite at 68 min. (B) Radial lamellipodia in SCs mediated continued contact with neurites after initial SC-neurite interaction. Shown are high magnification DIC images of a SC interacting with DRG neurites. Once initial contact between the SC leading edge (axial lamellipodium) and the neurites had been established, radial lamellipodia (arrow) emerged from the SC and remained in contact with the extending neurite (arrow with tail) over time. (C) Most interactions between SCs and DRG neurites were initiated by the axial lamellipodium (leading edge) of the SC. Bar graphs show the percentage of SC-neurite interactions involving axial lamellipodia (AL) and radial lamellipodia (RL); most interactions occurred between one axial and one radial lamellipodium $(n=40$ interactions). Scale bar $=10 \mu \mathrm{m}(\mathrm{A}$ and B).

Figure 5. Cell density and number of lamellipodia are not related contact-mediated migration of SCs. (A) Migration rate of SCs was not affected by the dell density. Bar graphs show migration rates in $\mu \mathrm{m} / \mathrm{min}$ for SCs cultured at different densities. No significant difference in migration rates was observed between the groups $(2000,4000$ and 6000 cells per well in a 
standard 24-well plate). $\mathrm{n}=40-44$ cells; 3 repeats. Error bars show standard error (SE); Anova with Tukey's post hoc test. (B) Migration rate of SCs was not related to the number of lamellipodia per cell. The graph shows the relationship between the migration rate (X-axis) and number of lamellipodia per cell (Y-axis). Linear regression analysis showed a coefficient of determination $\left(\mathrm{R}^{2}\right)$ of only 0.087 , suggesting that the number of lamellipodia is not a determinant of migration rate in SCs. $n=44$ cells.

Figure 6. Dynamic lamellipodia are actively involved in $\mathrm{SC}$ phagocytosis. (A-C) Lamellipodia contributed to SC phagocytosis of cell debris and bacteria. A series of timelapse fluorescence images show SCs (red) phagocytosing (A) green fluorescent axon debris, (B) heat killed E. coli bacteria and (C) live E. coli, with lamellipodia dynamically searching the local environment and interacting with the cell debris and bacteria. Arrows in A and B track the movement of debris/bacteria within the cell as determined by time-lapse microscopy. In $\mathrm{C}$, the arrow indicates bacteria already within the cell; the arrow with tail points to bacteria initially external to the SC, and then internalised within the cell. (D-F) The phagocytosed material was internalised into the SCs. High magnification confocal microscopy images show axon debris and bacteria internalised within SCs. Scale bar $=50 \mu \mathrm{m}$ in $\mathrm{A}, \mathrm{B} ; 25 \mu \mathrm{m}$ in $\mathrm{C} ; 20 \mu \mathrm{m}$ in D. Time-lapse movies of A-C are shown in supplementary movies 2-4.

Figure 7. Heregulin dramatically increases lamellipodial size, but does not affect phagocytic activity of SCs. (A, B) SC morphology in the absence (A) and presence (B) of heregulin. Heregulin $(50 \mathrm{ng} / \mathrm{ml})$ dramatically increased the area of SC lamellipodia (arrows) in comparison to control. Scale bar is $50 \mu \mathrm{m}$. (C-D) Heregulin did not affect the phagocytic activity of SCs with the amount of green fluorescent cell debris internalised within SCs in the 
absence (E) and presence of heregulin $(50 \mathrm{ng} / \mathrm{ml})$ after $12 \mathrm{~h}$. Scale bar is $50 \mu \mathrm{m}$. (E) Heregulin reduced the number of radial lamellipodia per cell. The number of radial lamellipodia was significantly reduced at all heregulin concentrations after $15 \mathrm{~min}$ of treatment. No significant changes were observed between $0-15$ min of treatment. (F) Heregulin caused a large increase in lamellipodial size. At $50 \mathrm{ng} / \mathrm{ml}$, heregulin treatment led to a significant increase in lamellipodial area, whilst no effect was observed at lower concentrations (one-way Anova with Tukey's post-hoc analysis; $n=30-40$ ).

Densitometric quantification of the amount of axonal debris phagocytosed within SCs after 3 $\mathrm{h}$ and $12 \mathrm{~h}$ incubation; graph shows a box and whisker plot. After both 3 and $12 \mathrm{~h} \mathrm{SCs}$ in control medium and heregulin-treated SCs exhibited a similar amount of accumulated intracellular axonal debris (one-way Anova with Tukey's post-hoc analysis; $\mathrm{n}=80$ ). ${ }^{*} \mathrm{p}<0.05 ; * * \mathrm{p}<0.01 ; * * * \mathrm{p}<0.001$. All error bars in this figure show SE.

Figure 8. The Rac and Rho pathways regulate SC phagocytosis, and Rac selectively regulates radial lamellipodia. (A) Rac inhibition reduced radial lamellipodia (arrowhead), but promoted axial lamellipodia (arrow). Large, broad axial lamellipodia (leading edges) were observed in cells treated with the Rac inhibitor NSC23760, whilst radial lamellipodia were smaller and fewer than in control conditions; this was most evident at the highest concentration of the inhibitor. (B) Rho inhibition led to loss of lamellipodia and focal adhesion points. After treatment with the Rho inhibitor Fasudil, cells showed a loss of adhesion points, and exhibited few lamellipodia. With higher concentrations of the Rho inhibitor, more cellular branches were observed, extensions were longer and thinner (arrow), and the cells formed a net-like structure. (C-F) Inhibition of Rac and Rho inhibited phagocytosis. SCs treated with the Rac inhibitor NSC23760 (C) showed internalised debris localised particularly around the nuclei and around broad lamellipodia, in contrast to control cells which had internalised the 
debris. At $50 \mu \mathrm{M}$, lamellipodia were inhibited, debris was attached to the cell but not internalised. Cells treated with the Rho inhibitor Fasudil (D) at higher concentrations (20 and $50 \mu \mathrm{M})$ continued to phagocytise debris, however, the debris was observed to be trapped between extensions and attached to the cell surface, similar to the treatment with the Rac inhibitor NSC23760 at $50 \mu \mathrm{M}$. (E-F) Treatment with either the Rac or the Rho inhibitor resulted in a concentration-dependent reduction of internalised axonal debris after 12 and 24 hours, as shown by densiometric quantification; at 20 and $50 \mu \mathrm{M}$, the reduction in phagocytic activity was significant when compared with control At 3 h, however, treatment with both inhibitors resulted in a significant increase in the phagocytic activity. No statistically significant difference was detected between the different concentrations, with the exception of the Rho inhibitor, at $10 \mu \mathrm{M}$ which induced a larger increase in the phagocytic activity than the other concentrations. Data were analyzed with one-way Anova with Tukey's post-hoc analysis; $\mathrm{n}=50-75$ cells). ${ }^{* * *} \mathrm{p}<0.001$. All error bars in this figure show SE. Scale bar $=50$ $\mu \mathrm{m}$.

Supplemental movie 1. Live-cell time-lapse movie showing the dynamic behaviour of DsRed-expressing SC lamellipodia over time. Lamellipodia appeared and disappeared along the cells, searching the environment. Time is in h:min.

Supplemental movies 2-4. Live-cell time-lapse movies showing how SC lamellipodia are actively mediating phagocytosis of axonal debris (2), heat-killed E. coli bacteria (3) and live E. coli (4). Time is in h:min. 


\section{REFERENCES}

1. Jin, F.Z., et al., N-WASp is required for Schwann cell cytoskeletal dynamics, normal myelin gene expression and peripheral nerve myelination. Development, 2011. 138(7): p. 1329-1337.

2. Nodari, A., et al., Beta4 integrin promotes myelin stability in the peripheral nervous system. Journal of the Peripheral Nervous System, 2005. 10: p. 67-67.

3. Nodari, A., et al., Betal integrin activates Racl in Schwann cells to generate radial lamellae during axonal sorting and myelination. J Cell Biol, 2007. 177(6): p. 106375.

4. Jessen, K.R. and R. Mirsky, The origin and development of glial cells in peripheral nerves. Nature Reviews Neuroscience, 2005. 6(9): p. 671-682.

5. Ness, J.K., K.M. Snyder, and N. Tapinos, Lck tyrosine kinase mediates betal-integrin signalling to regulate Schwann cell migration and myelination. Nat Commun, 2013. 4: p. 1912.

6. Pankov, R., et al., A Rac switch regulates random versus directionally persistent cell migration. J Cell Biol, 2005. 170(5): p. 793-802.

7. Sidera, K., et al., Involvement of cell surface HSP9O in cell migration reveals a novel role in the developing nervous system. J Biol Chem, 2004. 279(44): p. 45379-88.

8. Tello Velasquez, J., et al., Stimulating the proliferation, migration and lamellipodia of Schwann cells using low-dose curcumin. Neuroscience, 2016. 324: p. 140-50.

9. Tello Velasquez, J., et al., Low-dose curcumin stimulates proliferation, migration and phagocytic activity of olfactory ensheathing cells. PLoS One, 2014. 9(10): p. e111787. 
10. Wakatsuki, S., T. Araki, and A. Sehara-Fujisawa, Neuregulin-1/glial growth factor stimulates Schwann cell migration by inducing alpha5 betal integrin-ErbB2-focal adhesion kinase complex formation. Genes Cells, 2014. 19(1): p. 66-77.

11. Wang, Y., H.L. Teng, and Z.H. Huang, Intrinsic migratory properties of cultured Schwann cells based on single-cell migration assay. PLoS One, 2012. 7(12): p. e51824.

12. Melendez-Vasquez, C.V., S. Einheber, and J.L. Salzer, Rho kinase regulates schwann cell myelination and formation of associated axonal domains. J Neurosci, 2004. 24(16): p. 3953-63.

13. Novak, N., et al., N-WASP is required for membrane wrapping and myelination by Schwann cells. Journal of Cell Biology, 2011. 192(2): p. 243-250.

14. Nobes, C.D. and A. Hall, Rho, Rac, and Cdc42 Gtpases Regulate the Assembly of Multimolecular Focal Complexes Associated with Actin Stress Fibers, Lamellipodia, and Filopodia. Cell, 1995. 81(1): p. 53-62.

15. Wen, D.Z., et al., Structural and Functional-Aspects of the Multiplicity of Neu Differentiation Factors. Molecular and Cellular Biology, 1994. 14(3): p. 1909-1919.

16. Corfas, G., et al., Differential expression of ARIA isoforms in the rat brain. Neuron, 1995. 14(1): p. 103-15.

17. Alroy, I. and Y. Yarden, The ErbB signaling network in embryogenesis and oncogenesis: Signal diversification through combinatorial ligand-receptor interactions. Febs Letters, 1997. 410(1): p. 83-86.

18. Breuleux, M., et al., Heregulins implicated in cellular functions other than receptor activation. Molecular Cancer Research, 2006. 4(1): p. 27-37.

19. Meyer, D. and C. Birchmeier, Multiple essential functions of neuregulin in development. Nature, 1995. 378(6555): p. 386-90. 
20. Shah, N.M., et al., Glial growth factor restricts mammalian neural crest stem cells to a glial fate. Cell, 1994. 77(3): p. 349-60.

21. Mahanthappa, N.K., E.S. Anton, and W.D. Matthew, Glial growth factor 2, a soluble neuregulin, directly increases Schwann cell motility and indirectly promotes neurite outgrowth. J Neurosci, 1996. 16(15): p. 4673-83.

22. Marchionni, M.A., et al., Glial growth factors are alternatively spliced erbB2 ligands expressed in the nervous system. Nature, 1993. 362(6418): p. 312-8.

23. Corfas, G., et al., Mechanisms and roles of axon-Schwann cell interactions. J Neurosci, 2004. 24(42): p. 9250-60.

24. Stoll, G., S. Jander, and R.R. Myers, Degeneration and regeneration of the peripheral nervous system: From Augustus Waller's observations to neuroinflammation. Journal of the Peripheral Nervous System, 2002. 7(1): p. 13-27.

25. Fu, S.Y. and T. Gordon, The cellular and molecular basis of peripheral nerve regeneration. Molecular Neurobiology, 1997. 14(1-2): p. 67-116.

26. El-Barrany, W.G., et al., Ultrastructural changes of compressed lumbar ventral nerve roots following decompression. Saudi Med J, 2006. 27(7): p. 955-61.

27. Nazareth, L., et al., Olfactory ensheathing cells are the main phagocytic cells that remove axon debris during early development of the olfactory system. J Comp Neurol, 2015. 523(3): p. 479-94.

28. Nazareth, L., et al., Differing phagocytic capacities of accessory and main olfactory ensheathing cells and the implication for olfactory glia transplantation therapies. Mol Cell Neurosci, 2015. 65: p. 92-101.

29. Windus, L.C., et al., Stimulation of olfactory ensheathing cell motility enhances olfactory axon growth. Cell Mol Life Sci, 2011. 68(19): p. 3233-47. 
30. Windus, L.C., et al., Motile membrane protrusions regulate cell-cell adhesion and migration of olfactory ensheathing glia. Glia, 2007. 55(16): p. 1708-19.

31. Windus, L.C., et al., Lamellipodia mediate the heterogeneity of central olfactory ensheathing cell interactions. Cell Mol Life Sci, 2010. 67(10): p. 1735-50.

32. Hazenbos, W.L., et al., Virulence factors determine attachment and ingestion of nonopsonized and opsonized Bordetella pertussis by human monocytes. Infect Immun, 1994. 62(11): p. 4818-24.

33. Tomita, K., et al., The neurotrophin receptor p75NTR in Schwann cells is implicated in remyelination and motor recovery after peripheral nerve injury. Glia, 2007. 55(11): p. 1199-208.

34. Gaudet, A.D., P.G. Popovich, and M.S. Ramer, Wallerian degeneration: gaining perspective on inflammatory events after peripheral nerve injury. $\mathrm{J}$ Neuroinflammation, 2011. 8: p. 110.

35. Griffin, J.W. and W.J. Thompson, Biology and pathology of nonmyelinating Schwann cells. Glia, 2008. 56(14): p. 1518-31.

36. Panni, P., et al., Phagocytosis of bacteria by olfactory ensheathing cells and Schwann cells. Neurosci Lett, 2013. 539: p. 65-70.

37. Levi, A.D.O., et al., The Influence of Heregulins on Human Schwann-Cell Proliferation. Journal of Neuroscience, 1995. 15(2): p. 1329-1340.

38. Birchmeier, C. and K.A. Nave, Neuregulin-1, a key axonal signal that drives Schwann cell growth and differentiation. Glia, 2008. 56(14): p. 1491-7.

39. Gambarotta, G., et al., Neuregulin 1 role in Schwann cell regulation and potential applications to promote peripheral nerve regeneration. Int Rev Neurobiol, 2013. 108 : p. 223-56. 
40. Barton, M.J., et al., The Glia Response after Peripheral Nerve Injury: A Comparison between Schwann Cells and Olfactory Ensheathing Cells and Their Uses for Neural Regenerative Therapies. Int J Mol Sci, 2017. 18(2).

41. Ekberg, J.A., et al., The migration of olfactory ensheathing cells during development and regeneration. Neurosignals, 2012. 20(3): p. 147-58.

42. Ekberg, J.A. and J.A. St John, Crucial roles for olfactory ensheathing cells and olfactory mucosal cells in the repair of damaged neural tracts. Anat Rec (Hoboken), 2014. 297(1): p. 121-8.

43. Jessen, K.R. and R. Mirsky, The repair Schwann cell and its function in regenerating nerves. J Physiol, 2016. 594(13): p. 3521-31.

44. Melli, G. and A. Hoke, Dorsal Root Ganglia Sensory Neuronal Cultures: a tool for drug discovery for peripheral neuropathies. Expert Opin Drug Discov, 2009. 4(10): p. 1035-1045.

45. Dong, Z., et al., Neu differentiation factor is a neuron-glia signal and regulates survival, proliferation, and maturation of rat Schwann cell precursors. Neuron, 1995. 15(3): p. 585-96.

46. Chen, Z.L., W.M. Yu, and S. Strickland, Peripheral regeneration. Annu Rev Neurosci, 2007. 30: p. 209-33.

47. Benninger, Y., et al., Essential and distinct roles for cdc42 and racl in the regulation of Schwann cell biology during peripheral nervous system development. Journal of Cell Biology, 2007. 177(6): p. 1051-1061.

48. Hall, A. and C.D. Nobes, Rho GTPases: molecular switches that control the organization and dynamics of the actin cytoskeleton. Philosophical Transactions of the Royal Society B-Biological Sciences, 2000. 355(1399): p. 965-970. 
49. Nobes, C.D. and A. Hall, Rho, Rac and Cdc42 Gtpases - Regulators of Actin Structures, Cell-Adhesion and Motility. Biochemical Society Transactions, 1995. 23(3): p. 456-459.

50. Cheng, H.L., et al., GTPases and phosphatidylinositol 3-kinase are critical for insulin-like growth factor-I-mediated Schwann cell motility. Journal of Biological Chemistry, 2000. 275(35): p. 27197-27204.

51. Nakaya, M., et al., Opposite effects of rho family GTPases on engulfment of apoptotic cells by macrophages. J Biol Chem, 2006. 281(13): p. 8836-42.

52. Nakaya, M., et al., Spatiotemporal activation of Rac1 for engulfment of apoptotic cells. Proc Natl Acad Sci U S A, 2008. 105(27): p. 9198-203.

53. Mao, Y. and S.C. Finnemann, Regulation of phagocytosis by Rho GTPases. Small GTPases, 2015. 6(2): p. 89-99.

54. Sepp, K.J. and V.J. Auld, RhoA and Racl GTPases mediate the dynamic rearrangement of actin in peripheral glia. Development, 2003. 130(9): p. 1825-1835. 


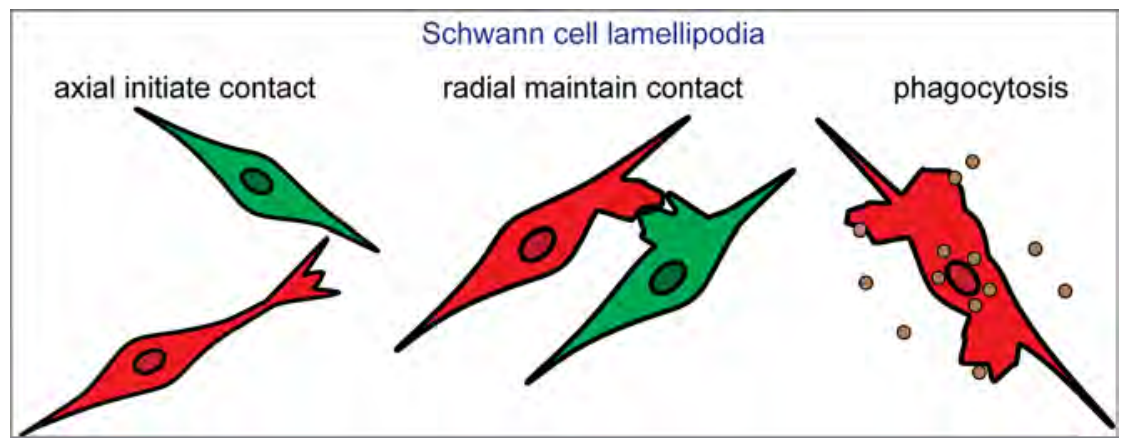

Graphics Abstract 
A

B

Ch
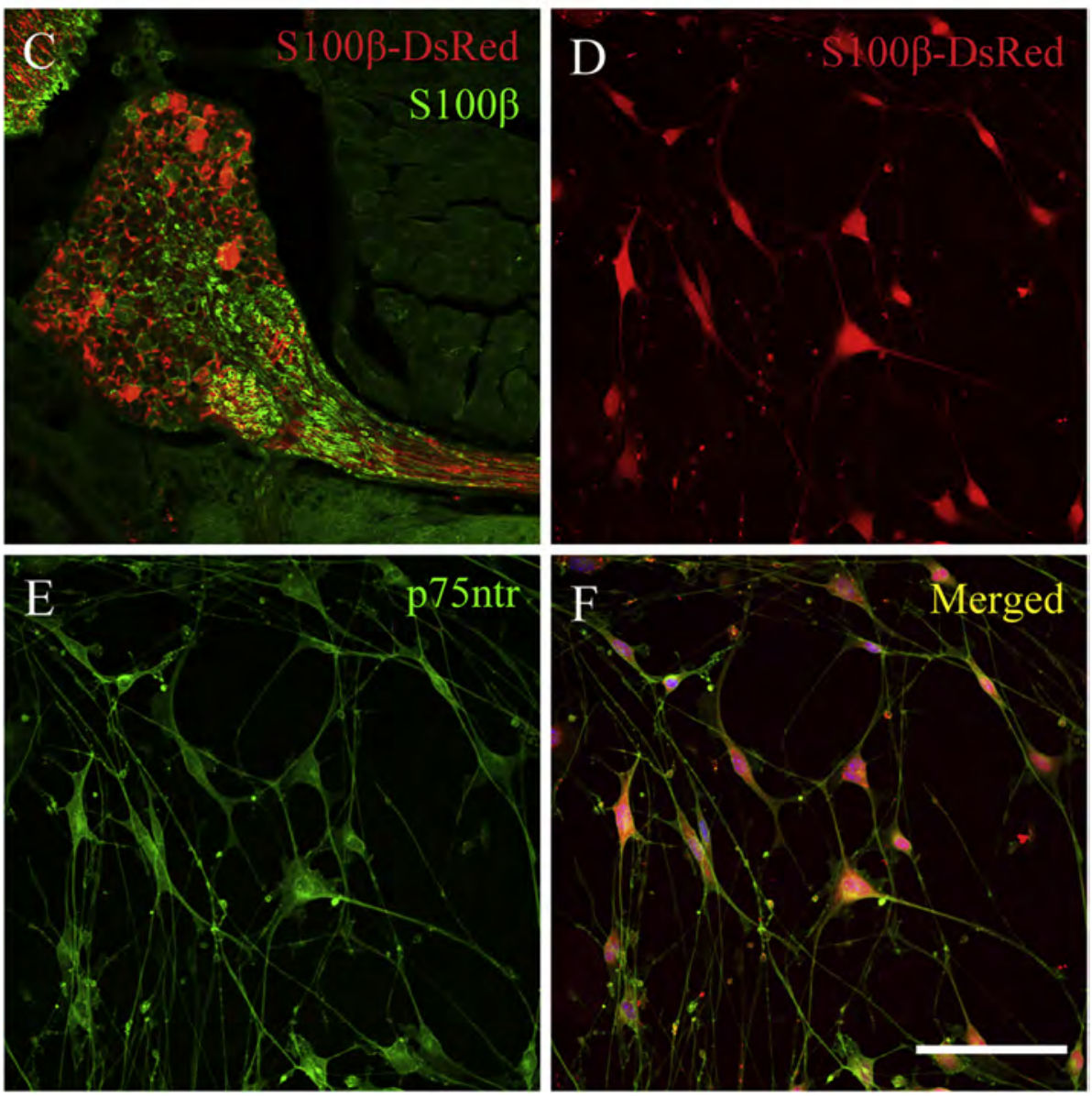

Figure 1 


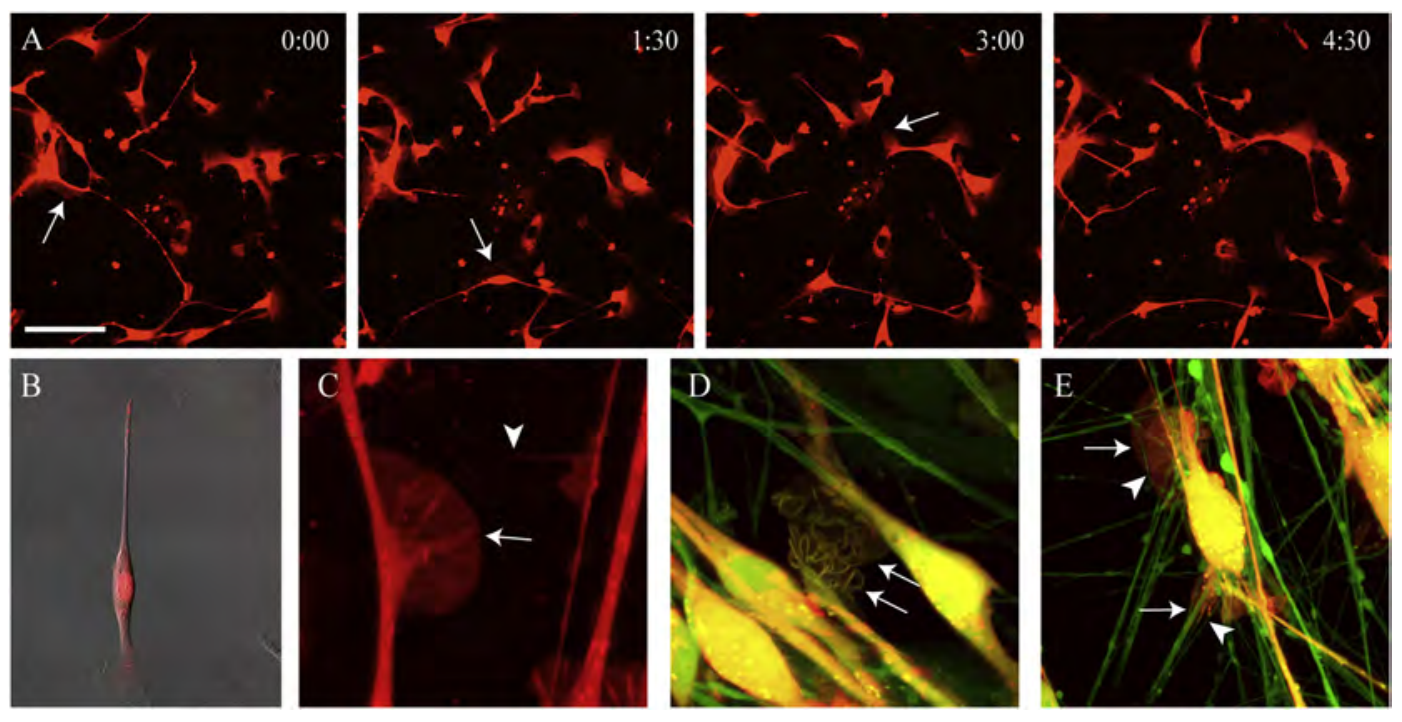

Figure 2 

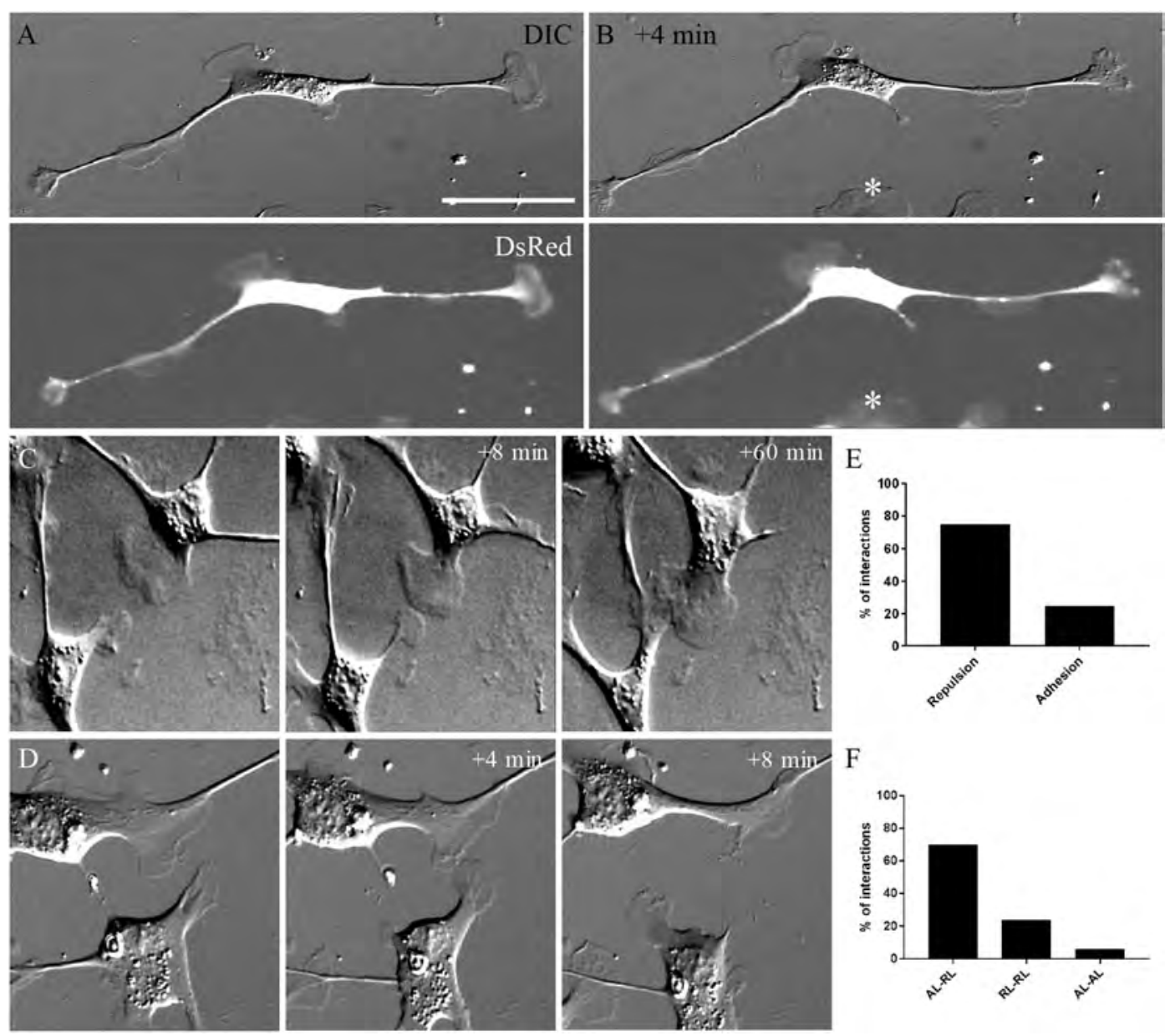

E
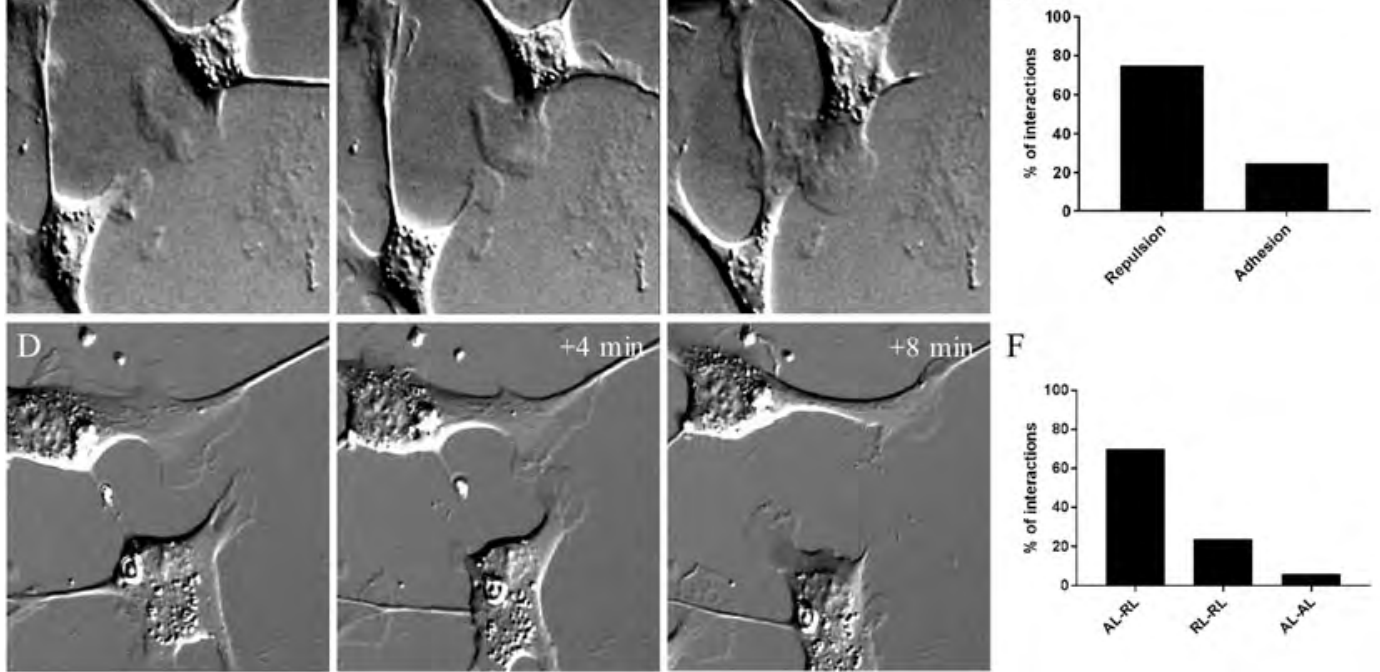

Figure 3 


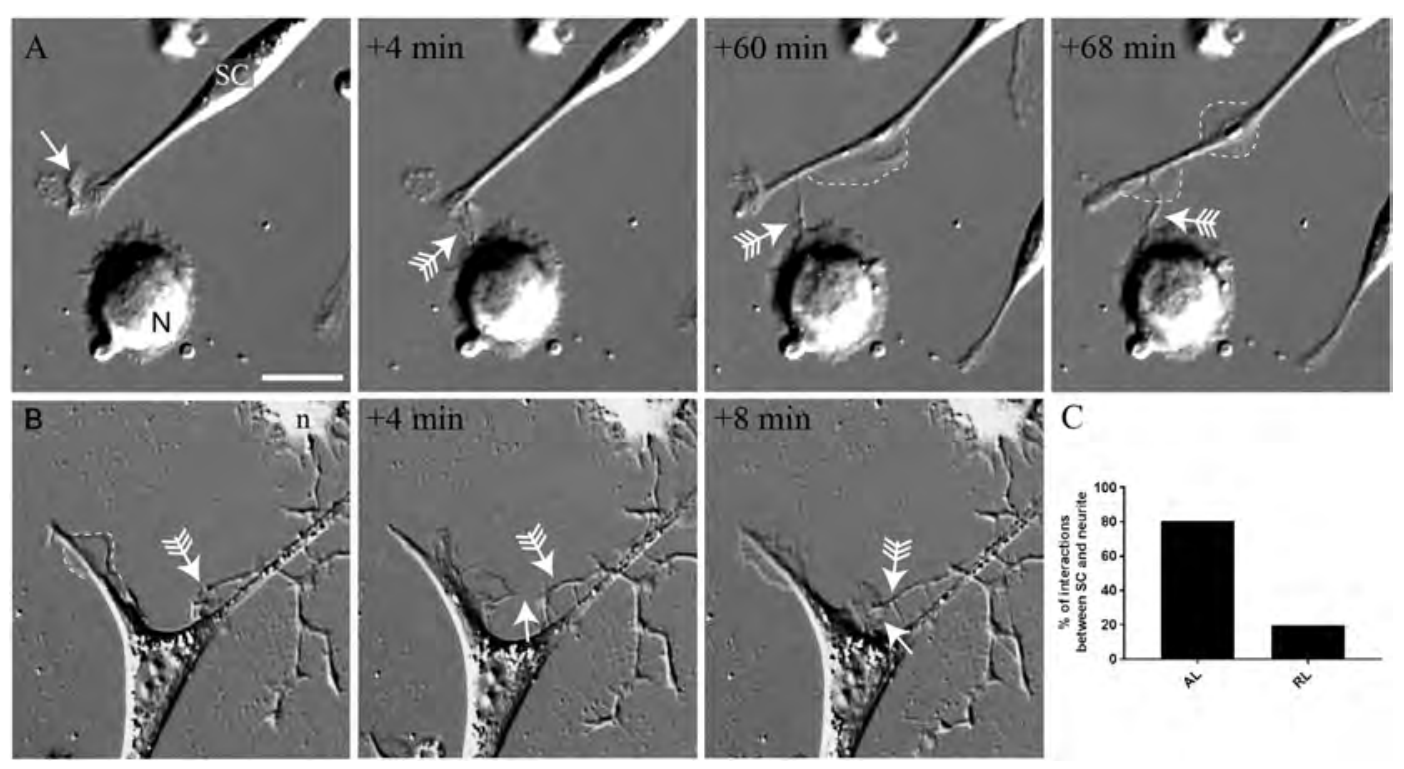

Figure 4 

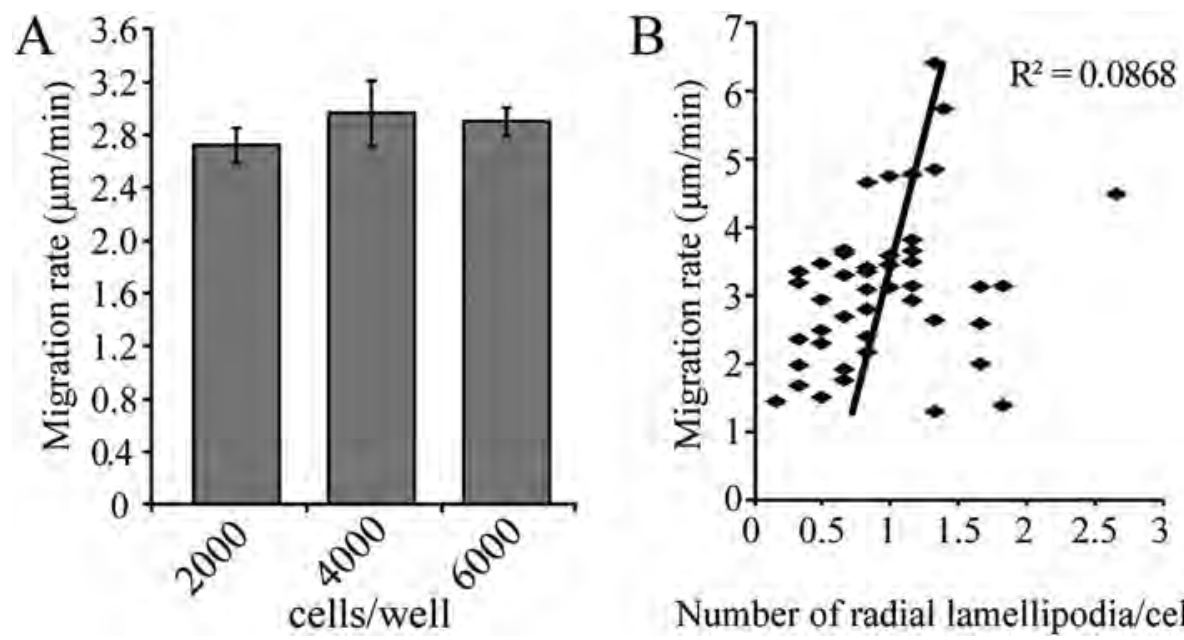

Number of radial lamellipodia/cell

Figure 5 


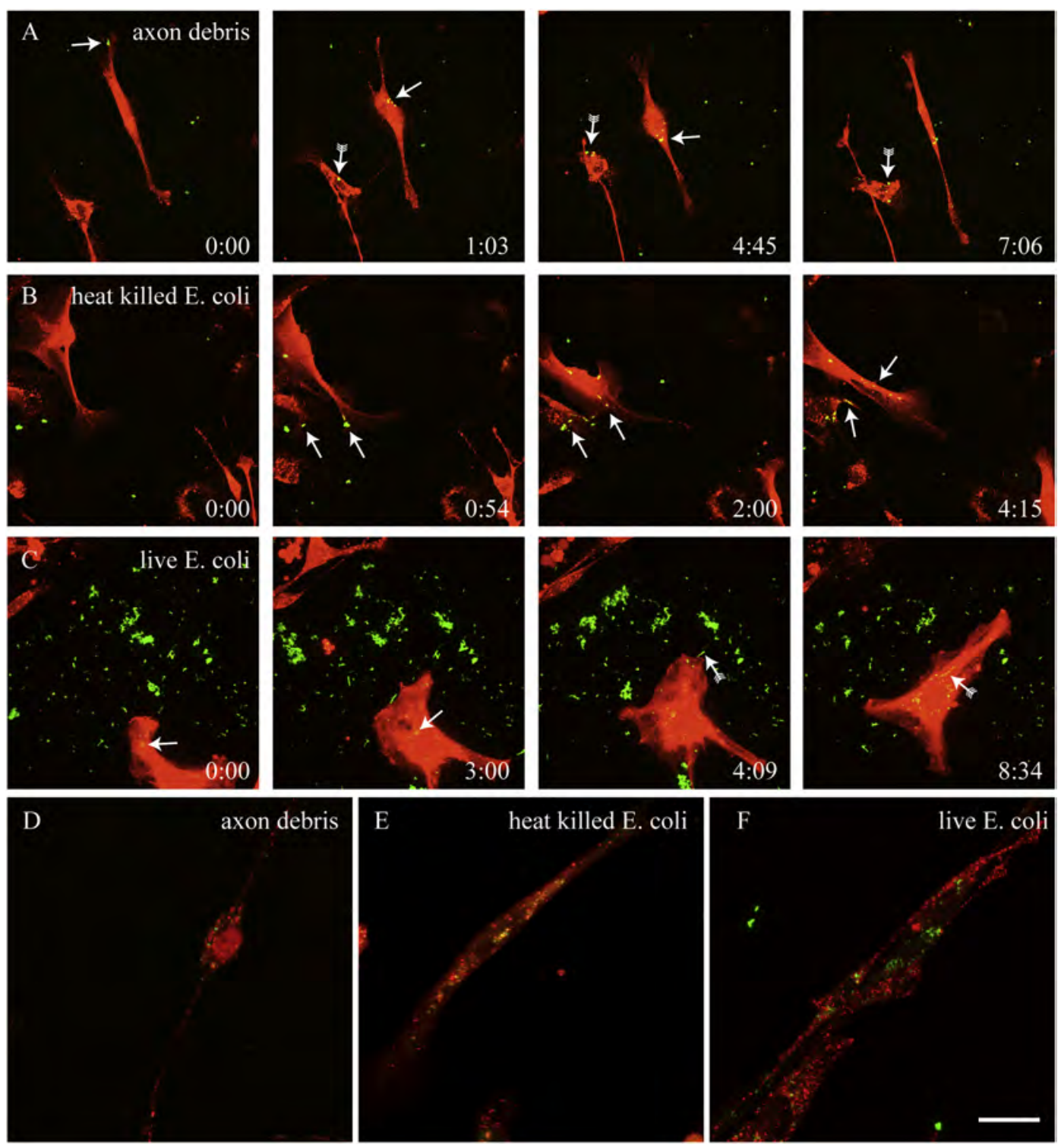

Figure 6 


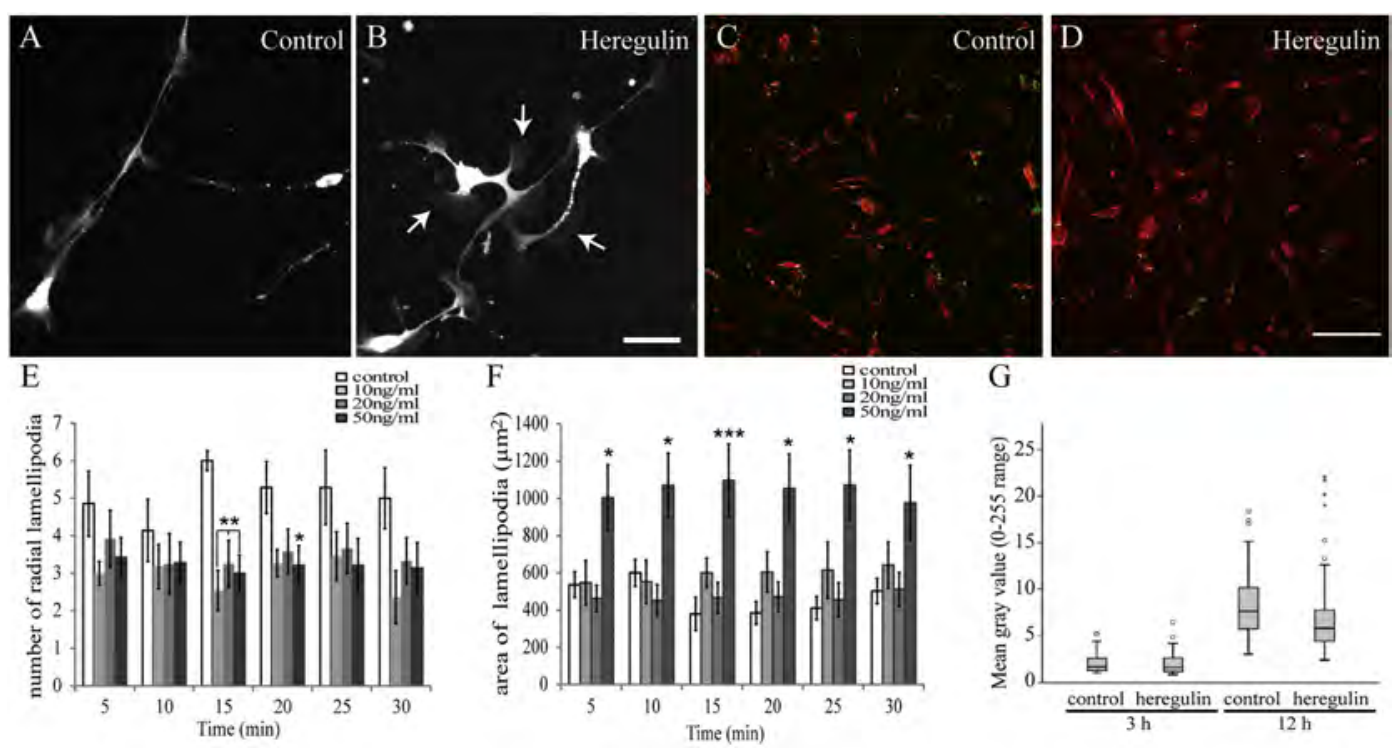

Figure 7 

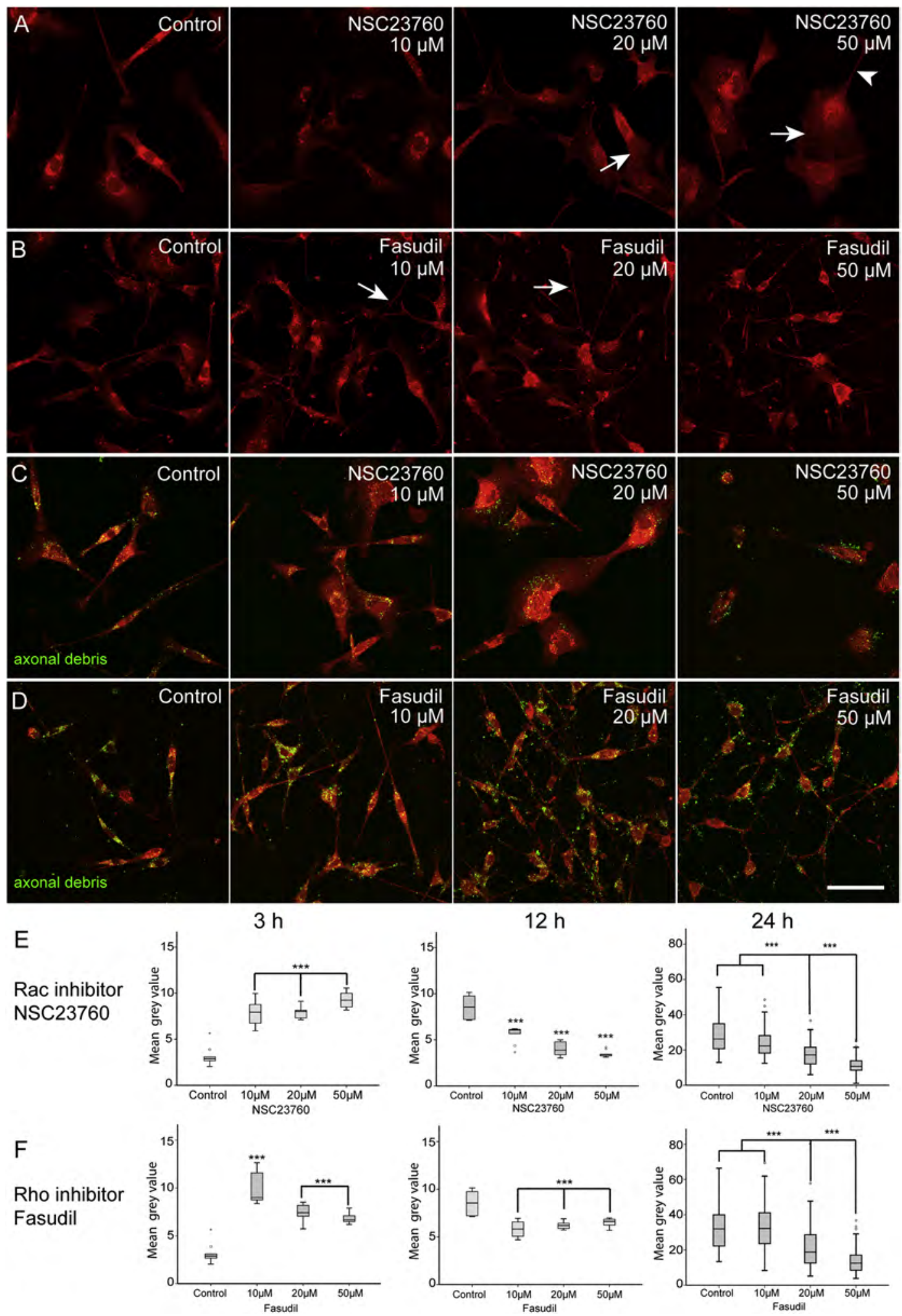


\section{Accepted Manuscript}

Schwann cell lamellipodia regulate cell-cell interactions and phagocytosis

Johana Tello Velasquez, James A. St John, Lynn Nazareth, Jenny A.K. Ekberg

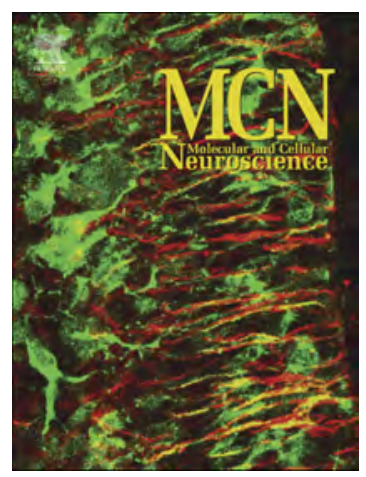

PII:

S1044-7431(17)30291-9

DOI: https://doi.org/10.1016/j.mcn.2018.01.001

Reference: YMCNE 3267

To appear in: Molecular and Cellular Neuroscience

Received date: 30 August 2017

Revised date:

2 January 2018

Accepted date:

9 January 2018

Please cite this article as: Johana Tello Velasquez, James A. St John, Lynn Nazareth, Jenny A.K. Ekberg, Schwann cell lamellipodia regulate cell-cell interactions and phagocytosis. The address for the corresponding author was captured as affiliation for all authors. Please check if appropriate. Ymcne(2017), https://doi.org/10.1016/j.mcn.2018.01.001

This is a PDF file of an unedited manuscript that has been accepted for publication. As a service to our customers we are providing this early version of the manuscript. The manuscript will undergo copyediting, typesetting, and review of the resulting proof before it is published in its final form. Please note that during the production process errors may be discovered which could affect the content, and all legal disclaimers that apply to the journal pertain. 